\section{School Network Reviews: A Framework of Questions for Discussion}

\section{CATHERINE SAVAGE}

\section{Abstract:}

The fundamental issue faced by the Taskforce to Review Education Administration (which produced the Picot Report in 1988) was essentially the same issue that underlies the current School Network Reviews: Is school administration to be managed centrally or locally? How do we achieve a balance between national interests and local interests of schools? The current five-year Review moratorium provides a window of opportunity for considering fundamental aspects of our education system embedded in the Reviews, and some more time to examine their ramifications for families and whānau, communities and districts, early childhood centres and their partnerships with schools, and for student learning in general. This article examines the balance between centralisation and localisation, and frames some key questions about the Network Review process for discussion.

elected regions and districts of New Zealand with large numbers of small schools have been under review by the Ministry of Education since 2001. Following concerns expressed by parents and communities about these School Network Reviews, a five-year moratorium on the review process was declared in late 2004. This was designed to provide more time for discussion and examination of issues that had emerged from the reviews so far, and a breathing space for more extended consideration of future ramifications.

The intent of the Network Reviews, according to the Ministry, was, "to strengthen networks of schools against future school roll declines by reducing potential future uncertainties and through freeing up resources that can be directed towards increased learning" (Ministry of Education, 2004a). Since 2001, selected primary and secondary schools in nineteen school districts have been reviewed. The outcome of a review is a decision that can be made for a school to close, merge, continue, or have a change of "class". The Minister also has the prerogative to establish a new school (Education Act, 1989).

The reviews stem from a series of investigations and recommendations for educational reform which date from 1988. A pervasive concern at that time was the structure of school administration, which was viewed as being heavily centralised and insufficiently responsive to local needs. For the purposes of this paper, it is useful to formulate the broad concerns of parents, communities and school staff since that time as a single fundamental question: To what extent should school administration and responsibility be centralised, and to what extent should it be localised?

This article considers four viewpoints on the topic of how to obtain an optimal balance between national interests and local interests in education. Only brief reference will be made here to the legislative origins and legal responsibilities impinging on the issue. Those constitutional formulations are embodied in the Education Amendment Act of 1989 and its later amendments. The intent of this article is to frame the educational issues so that key questions can be asked which will inform discussion and encourage examination. The frame consists of four perspectives:

- The perspective of homes, families and whānau;

- The perspective of communities;

- The perspectives of partnerships of early childhood centres with families, communities, and schools;

- The perspective of schools for providing opportunities for students to learn and achieve.

A brief historical overview of the antecedents to the School Network Reviews is given in the next section. The four perspectives will then be discussed and followed by a series of questions which warrant examination.

\section{Background}

The current system of schooling in New Zealand received legislative approval in October 1989 through the Education Act of that year. The new system was based on the White Paper titled Tomorrow's Schools: The Reform of Education Administration in New Zealand (Department of 
Education, 1988b) This declared, "The basic unit of education administration will be the individual school or early childhood centre" (p. 3). The immediate antecedent to the White Paper was an earlier report prepared by the Taskforce to Review Educational Administration, Administering for Excellence: Effective Administration in Education (Department of Education, 1988a), commonly known as The Picot Report, after the name of its chairman, Brian Picot. The rationale behind the Taskforce recommendations contained in this report was that school administration in New Zealand had become "over centralised and overly complex" (p. xi)

The common theme of the Picot Report, Tomorrow's Schools, and the Education Act was the need to restructure the national education system at both the central and local levels. Mitchell summarized the reforms as, "characterised by a substantial devolution of responsibility and authority from the centre to the individual learning institutions" (1993, p. 1). In essence, schools were to become self-managing, in a partnership with the community and the government.

In his summary of the reforms, Mitchell reminds us that "much of what was included in the Picot Report and the subsequent Tomorrow's Schools was substantially grounded in the earlier reports and did not, therefore, represent a dramatic departure from past perceptions of the need for changes in the administration of education in New Zealand" (p. 18). Among the earlier reports was advice by the Treasury, which advocated a market approach to educational administration that asserted, "education shares the main characteristics of other commodities traded in the market place" (The Treasury, 1987, p. 33). In its briefing papers to the incoming government, its authors signaled that education should be managed as a "public good", rather than in the "good of the public" (cited in Grace, 1989, p. 208). According to McKenzie (1996), the Treasury's perspective on education was intended to create market behaviour by parents that flowed on to create a competitive, efficient market-responsive school system.

The Picot Taskforce recommended which elements of the school system would best be managed at a national level, while making provision for locally managed schools operating in response to local interests. For the purpose of this article, the Taskforce could be regarded as having four main objectives in its report (Department of Education, 1988a):
Access: "Every learner should gain the maximum individual and social benefit from the money spent on education" (p. 3).

Equity: "Education should be fair and just for every learner regardless of their gender, and/or their social, cultural or geographic circumstances" (p. 3).

Localisation: "People in the institution should make as many of the decisions that affect the institution as possible" (p. xi).

Partnership: "The running of learning institutions should be a partnership between the teaching staff (the professionals) and the community" (p. xi).

The Taskforce grappled with the centralising or localising issue by acknowledging that some matters are a concern of the state, but "wherever possible the government should make only those administrative decisions it needs to take and that all other administrative decisions should pass to the learning institution" (p. 5).

When the White Paper based on the Picot Report was introduced, Prime Minister and Minister of Education, Rt Hon. David Lange, stated, "Tomorrow's Schools outlines the most thoroughgoing changes to the administration of education in our history" (1998b, p. 1). A year later the reforms passed into legislation as the Education Act of 1989. In a major policy analysis of the reforms ten years later, Smelt noted:

The structural changes which have occurred in education in New Zealand over recent years are not unique. A common feature of reforms in many countries has been the move towards school-based management and decision-making .... The shift in control from the centre to individual schools which occurred in 1989 can be seen as part of a world-wide development. (1998, p. 4)

However, he also notes, "the reforms go further than reforms to date in other countries" (p.ix) and, "By international standards, New Zealand's reforms are dramatic and the New Zealand governance structure - both at system level and within schools - is unusual" (p. 18).

The 1989 Education Act disestablished the Department of Education and created the Ministry of Education. Various elements of the Picot Taskforce recommendations were modified, omitted or reformulated, but in essence the broad reforms recommended by Picot and embodied in Tomorrow's Schools were accepted. Most notably, the restructuring resulted in the abolition of the middle layer of bureaucracy (Mansell, 1993, p. 2). 
Under the Act the Minister of Education continued to have the prerogative to close, merge, continue or change the "class" of schools; he could also establish a school. In 2001 the Ministry began to exercise this prerogative, as it sought to ensure all children had access to a quality education, by reorganizing schools through the Network Review process.

The Ministry observed that changing demographics in New Zealand had resulted in under-utilized education resources. It noted that there was continued funding of schools with falling rolls and future projections of further roll decline. The proposed benefits of the school reorganisation following the Network Reviews were stated as:

- Planning that takes account of demographic changes and its impact on schooling requirements

- Educational resources that are used widely and well

- Unused and under-used school resource would be released and ploughed back into the school communities

- More money would become available to invest in better teaching and learning resources

- School would have workable rolls for many years

- More cooperation between schools was to be encouraged

- Teachers would have a more viable and supportive professional community to enhance their development and benefit their student learning

- Community involvement in schools would be strengthened

- New models for the delivery of education would be considered.

(Ministry of Education, 2004a)

Now, fifteen years after the recommendations of Tomorrow's Schools were implemented, we have an environment in which many communities feel a strong sense of ownership toward their schools. Recently, Robust (2002) has commented that:

While the school has been a crucial focal point of the community if it should become an uneconomical body then the government has policy in place to close it and amalgamate it with other schools in the area. The logistics of this would serve greatly to disempower people despite the original intention of Tomorrow's Schools. (p. 13)

The issue of centralising and localising administration confronts centres and schools in many ways and at many levels. The boards of trustees and staff of centres/schools seek to provide every learner with opportunities that ensure maximum individual and social benefits from the money spent on education, while also ensuring that the self-determining functions and responsibilities of schools are not lost.

Given the historical concern for participation, partnership and community-administered schools initiated by the Picot Taskforce, it is time to re-examine the issues that once again face many of our schools. There are four perspectives from which the Network Reviews so far can be considered; the family perspective, the community perspective, the centre/home and school partnership perspective, and the school plan perspective.

\section{The perspective of family and wh nau}

The Picot Taskforce proposed changes to the school system structure that would promote the involvement and interest of parents. It approached the issue with the view that "parents want to be involved more fully in various facets of the education of their children and the overall direction of our proposal is to encourage this" (Department of Education, 1988a, p. 4). It concluded, "Parents, learners and the community [emphasis in original] will have greater opportunities to influence the kind and quality of education offered. They will also have greater responsibility for helping reach their community's - and the nation's education objectives" (p. 98).

To promote parents' interests, the Taskforce envisaged a Parent Advocacy Council as one of the four basic administrative structures. The Council was intended as an independent body funded by the state, and reporting directly to Parliament. Although the council was established under the Tomorrow's Schools paper, it was abolished in 1991 by the National Government, which believed that parent's interests could be met by existing structures such as the Ombudsman and the Human Rights Council, an argument specifically considered and rejected by the Picot Taskforce (Fiske \& Ladd, 2000, p. 57).

The concept of families in New Zealand is complex, as it not only refers to a common western view of the nuclear family but also to the extended family/whānau group of grandparents, aunts, uncles, and cousins (Biddulph et al., 2003). The importance of whānau to Māori culture is paramount, as it not only explains a basic social unit, but also the significance of kinship, identity and wellbeing (Pere, 1997). Recent research in New Zealand supports the view of the Picot Taskforce that 
participation and partnerships in education with Māori whānau promote achievement for Māori students (Bishop, Berryman, Tiakiwai \& Richardson, 2003, p. 97).

The role of whānau in the education of Māori children was a priority for the Taskforce, as Māori increasingly wished to be involved in the education of their children. The Taskforce recognised that theirinterests were often overlooked or subverted by the central policies. It aimed to reorganise school administration to allow whānau more autonomy, increase access to the classroom, and exercise an increasing, more equitable measure of influence over their children's education (1988a, p. 66). The 1989 Education Act bought about the creation of school Boards of Trustees and formalized the partnership between family, whānau, the learning institutions and the government.

After ten years of studying the reforms, Wylie reported, "over time, the boards of trustees appear to be becoming more representative of parents as a whole in terms of ethnicity, gender, and socioeconomic status" (1999, p. 194). She concluded, "Parent satisfaction levels with the quality of their child's education were high as the reforms began. They have not increased further. Nor have they declined" (p. 193). However, Wylie observed that

Low-decile and high-Māori-enrolment schools are also more likely to have gained least from the reforms, and may even have gone backwards, suffering falling rolls at a time when primary rolls were generally rising (although not in all regions), carrying additional administrative costs and - although in receipt of additional funding from government - drawing on fewer voluntary resources, and continuing to have lower parental involvement. (p. 193)

Parents are very influential in their children's development, and their participation in the local school setting and in the general educational achievement of their children should not be under-estimated. The Review process acknowledges the role of parents in schools through consultation. Forinstance, the Education Amendment Act of 1989 insists that in the situation of a merger:

Each Board of a school concerned has made reasonable effort to consult the parents of students enrolled full time at the school about the proposed merger; and in the case of each school, most parents favour the proposed merger. (p. 141)
This raises several questions in terms of relocation, and possible dislocation, for families.

Questions:

When schools are reorganized by Network Review decisions, to what extent are family/whānau involvements in schools likely to be affected?

- What are the implications for family structure, in particular whānau development, when a school is reorganised or closed?

- In what ways could the Network Review reorganisation facilitate the participation of family/whānau in schools?

- Do parents require representation at a national level, as the Taskforce intended? If so, what purposes and functions would such a council serve?

\section{The perspective of the community}

The administrative system proposed by the Picot Taskforce emphasized local autonomy and participation: "This can only make the learning institution even more a focal point for the community than it is now" (Department of Education, 1988a, p. 98)

The Taskforce believed its reforms would result in positive social consequences for local communities. The report acknowledged that the learning institution in many instances acted as a central meeting place for the diverse groups within a particular community. If communities had more power to make decisions about the way in which their school operated, "Teaching will be much more responsive to changing educational needs and particularly to the aspirations of groups that had traditionally felt overlooked" (p. 98). The Picot Taskforce intended communities to have an active voice in education. Although no formal structures were envisaged at a district level, it recommended a Community Education Forum. The purposes of these forums were to discuss such matters as policy initiatives, local conflicts of interest, the development of new national curriculum objectives, and the opening and closing of institutions (p. 54). The 1989 Education Act made no specific mention of the forums, and by 1991 the National Government had passed legislation abolishing them (Fiske \& Ladd, 2000, p. 108).

Under Tomorrow's Schools each school community was to have its own set of objectives within the overall education objectives set by the state. These objectives were to reflect the particular needs of the community in which the institution was located and would be clearly set 
out in the charter, which would "act as a contract between the community and institution, and the institution and the state" (p. 44).

The mechanism by which this would be realized in the Tomorrow's Schools reforms was to be the Board of Trustees. Since the 1989 reforms, the Boards of Trustees have maintained control over the day-to-day administration of schools. This move has seen community involvement in many aspects of educational administration, from property management, to employment of principals and teachers, through to the maintenance of student behavioural standards by means of their participation in the stand-down and suspension process.

New Zealand communities are becoming more diverse as a result of urbanisation and migration, and policies of inclusion. Since the days of the Picot Taskforce, schools have been facing significant changes in their populations, not only through declining rolls in some areas, but also through the inclusion of students with a range of learning and behavioural disabilities, migrant and refugee populations and students from non-English speaking backgrounds. The increased diversity of our school communities requires schools to be more responsive to a wider range of needs within the community. This may have implications for school closures and mergers as reorganized schools set out to reflect reconstituted cultural communities.

It is currently believed that peers play a significant role in the transmission of both positive and negative influences. In New Zealand there are significant group disparities, not only in school populations, but also more generally in youth justice statistics, including truancy and bullying. These pose significant issues for the reorganisation of schools as communities are subsequently reorganised, with both positive and negative influences on students.

The process of Network Reviews involves community consultation with the individual Boards of Trustees of each school, whose members were elected to represent the community perspective and need. The 1989 Education Act outlines the legislative commitment the Ministry of Education must make during any school reorganisation. For instance, in the case of a merger, the board of the school concerned must join in making a written application to the Minister (Education Act, 1989, 156d).

The Ministry has stated a commitment to the development of communities within New Zealand. The recent Statement of Intent 2004-2009 declares that, "communities are integral to student achievement", and the role of "the institution is to engage families and communities in education" (Ministry of Education, 2004c). There are thus several aspects of the Network Reviews that need to be considered in relation to future community and school development, since the impact of reorganisation can have both positive and negative effects.

\section{Questions:}

When schools are reorganized under the Network Review process what consequences are likely to occur for local community involvement in education?

- How will student learning be influenced when the situation and context of the school community is reorganised?

- How will mergers and closures of schools assist in achieving the goal to reduce the disparities occurring in school achievement?

- In what ways will the school reorganisation strengthen communityschool cohesion and networks?

- Would a Community Education Forum assist as intended in network review decision-making, and in the development of reorganised schools and communities.

\section{The perspective of centre, home and school partnerships}

The Picot Taskforce had a vision that, "The running of learning institutions should be a partnership between the teaching staff (the professionals) and the community. The mechanism for creating such a partnership will be a board of trustees" (1988a, p. xi). This vision was emphasised in a concluding note:

The social consequences of our proposals will also be significant for local communities. In many instances the learning institution acts as the central meeting place for the diverse groups within a particular community. We are proposing a system that emphasises local autonomy and participation - this can only make the learning institution even more a focal point for the community than it is now. (p. 98)

The Taskforce recognized that the early childhood education sector needed to be included, so as to reduce its fragmentation and complexity. Consequently, early childhood education became incorporated in the proposed reforms as a learning institution, although, "The role of the board of trustees will differ in some detail between the three sectors early childhood, compulsory schools (primary and secondary), and tertiary" (p. 45) 
Effective centre/school and home partnerships can strengthen support for learning in both settings, according to Biddulph et al. (2003), and there is research which indicates that the partnership aspects of education are perhaps the strongest indicator of success. "These partnerships can not only benefit the well-being, behaviour and achievement of children and young people but can persist into adult life and civic participation" (p. 143).

The closure and merger of schools and the redistribution of resources under the Network Review may have a significant impact on the centre/school and home partnerships in our communities. This may be particularly relevant in early childhood centres, as Lythe (1997) reports, "Early Childhood Centres became an integral part of the fabric of the family life, part of the overall network of community relationships" (Lythe, 1997, p. 148).

There have been indications that the concept of partnerships in school administration has gradually gained in viability. Wylie (1999) concludes: "New partnerships have been formed through the boards of trustees and school professionals, partnerships which usually work well and constructively for the benefit of the students in particular schools" (p. 194).

Under the Network Review reorganization, local schools may be closed or merged, creating larger more centralised schools. This may have implications for early childhood centres dislocated from their original local school community. They may then be required to establish new partnerships with reconstituted schools, which may not be in their immediate neighbourhood.

\section{Questions:}

When schools merge or close under a Network Review decision, what consequences may occur for early childhood centres, home and school partnerships?

- How will Network reorganisation promote partnerships between centre/school and home?

- In what way will early childhood services and home/school partnership services be affected as schools become increasingly centralized?

- What implications does school network reorganisation have for existing centre/home and school partnership initiatives?

\section{The perspective of the school plan}

The Picot Taskforce intended that each school would operate in a manner reflecting the uniqueness of its community, while still functioning in accordance with national government objectives. The Taskforce recommended the writing of a school charter which would act as a contract between the government and the school, and the school and the community. The charter was expected to define the purposes of the institution and the intended outcomes for students. The charter would take into account:

- The particular interests of the students

- The special skills and qualifications of the staff

- The resources of the community

- The particular wishes of the institution's community.

(Department of Education, 1988a, p. 45)

In the Education Amendment Act of 1995 the School Charter was replaced with the School Plan.

Instead of the current requirement to have a school charter and a number of other plans specified by various pieces of legislation, school Boards of Trustees will be required to prepare and annually update a school plan. (p. 4)

This document has both a long term strategic planning section and an annual planning section which are formed and updated in consultation with parents of students and the staff of the school. The Annual School Plan provides direction on how schools will consult with parents and ensures that Boards take, "all reasonable steps to discover and consider the view and concerns of Māori communities living in the geographic area that the school services in the development of a school plan" (p. 4).

There have been indications that the operation of school plans has become more effective over time. However, as Wylie concludes from her comprehensive ten-year study, "We probably need to acknowledge that it takes time to change schools, and that schools cannot focus equally well on everything at the same time" (1999, p. 197)

The reorganisation of schools under the Network Review implies the rewriting of school plans, the inputs for which may or may not be familiar. One of the ramifications of reorganised schools may be the increased likelihood that the school plan no longer reflects the needs of the students, school and community. 
Questions:

When schools are restructured under the Network Review process what consequences are likely to occur that impinge on school planning?

- What are the implications for school plans as school communities become increasingly diverse through consolidation?

- How will schools ensure that the aspirations of the community include all aspects of an increasingly diverse community after reorganisation?

- As communities become more diverse through reorganisation and schools become increasingly consolidated, will schools experience more difficulty in reflecting community aspirations?

\section{Discussion}

The four perspectives outlined above provide four ways in which the whole review process can be observed, and many of the questions await well-researched answers. The benefits of the Network Review echo the recommendations of the Picot taskforce that "every learner should gain the maximum individual and social benefit from the money spent on education" (Department of Education, 1988a, p. 3). This poses a dilemma, as reorganisation may unbalance many of the other objectives that Tomorrow's Schools also defined. In particular, the move to centralise school administration may de-emphasize the principle of local schools educating local children.

As stated previously, this is not a new issue, nor is the notion of questioning the balance between centralisation and localisation. Smelt concluded that:

Overall, there is considerable potential to develop the existing system further. The current balance of interests and powers is by no means the only one possible within a Crown-owned but decentralized system, and the optimal balance is unlikely to have been struck as yet, given the dynamics and complexities of the reform process, the interest groups involved and the outcomes to date. (1998, p. 18)

The tradition of asking questions began with the implementation of the reforms throughout 1991 and 1992. Mitchell (1993) began by questioning the extent to which the system has been decentralised. He concludes his summation of the reforms by posing several questions:

- Has there been a transfer of greater responsibility from central to local institutions? Has there been a transfer of real power?
- Has the balance of control genuinely shifted between local and central authorities?

- And, perhaps even more importantly, have children benefited, and in what way have they benefited from the reforms in educational administration? (p. 18)

The questions arising from this article's perspectives of the "state of the Network Reviews" are intended to encourage discussion and examination. As the Taskforce intended, families have become increasingly involved in the operations of schools. In many of the small rural service towns that are currently under review, the falling rolls of increasingly smaller schools have meant that families have had to show significant ongoing commitment. It is important that the perspective with which we view the Network Reviews is grounded in a body of knowledge and discussion so that we can critically evaluate possible longer term impacts on our system.

The family and whānau in communities are the first point of support for many children. As reorganisation occurs, how will the placements of schools in the geographic region affect local whannau and extended families? The Ministry of Education has signaled its support for family and whānau, and its intent to develop strong partnerships between schools and families. In what ways will the Network Review assist in achieving these objectives? Research is needed then, not only on the effects of schooling on the community, but also on the effects of the relationship between community and school on children's learning. Better understanding of the reciprocal nature of the learning process in the formation of learning communities may assist us to understand the implications of school network reorganisation for student achievement.

To better understand the implications of the Reviews for school reorganisation, we need to investigate the role partnerships play in the community, in particular those partnerships established in early childhood settings. By centralizing our schools, are we going to isolate our early childhood centres and service providers? Or will the Network Reviews lead to the centralisation of other services in the community?

When schools reorganise, their school plans must immediately be revised. If the present tendencies continue, then one result will be a gradual shift towards larger schools. Since the communities they serve may not be consolidating, the representation of the community through the Board of Trustees could become disjunctive. One possible implication is that school and community become distanced from each other, and a sense of anomie occurs. 
Such a trend echoes the initial views of the Picot Taskforce, a trend also echoed in a summation by Wylie of the impact of the Tomorrow's Schools reforms in her report:

The Picot committee found frustration and a sense of powerlessness among school staff in relation to decisions made by the then Department of Education. This survey finds that, while people in schools have more immediate say, which they enjoy, their perception is that central government agencies appear to many in schools to be facing in another direction from their own, insisting that schools take paths that they do not want to take, and taking insufficient account of school views and experiences. (1999, p. 193)

The issue of achieving a balance between local and central administrative roles and management continues. The network review has emphasised the omission of the mid-layer bureaucracy under the Tomorrow's School's restructuring, without provision for the Parent Advocacy Council or Community Education Forums, as recommended by the Taskforce. Local school communities may now find themselves at odds with central decisions to reorganise, with no formal mediating body. Research and discussion are essential for securing an improved balance of representation and responsibility between local and central administration, and much more will be needed in the future if an optimal balance is to be achieved.

\section{References}

Ballantyne, A. L. (1997). Power or partnership: An analysis of the role and political positioning of the New Zealand School Trustees Association in the implementation of the "Tomorrow's Schools" reforms 1989-1994. Palmerston North: Massey University.

Biddulph, F., Biddulph, J., \& Biddulph, C. (2003). The complexity of community and family influences on children's achievement in New Zealand: Best evidence synthesis. Wellington: Ministry of Education

Bishop, R., Berryman, M., Tiakiwai, S., \& Richardson, C. (2003). Te Kotahitanga: The experiences of Year 9 and 10 Māori students in mainstream classrooms. Report to the Ministry of Education. Wellington: Ministry of Education.

Education Amendment Act. (1998). Wellington: Government Printer. Education Amendment Act. (1995) Wellington: Government Printer. Education Act. (1989). Wellington: Government Printer.
Fiske, E., \& Ladd, H. (2000). When schools compete: A cautionary tale. Washington, DC: Brookings Institution Press.

Grace, G. (1989). Education: Commodity or public good? British Journal of Educational Studies, 37(3), 207-221.

Department of Education. (1988a). Administering for excellence: Effective administration in education (Picot Report). Wellington: Government Printer.

Department of Education. (1988b). Tomorrow's schools: The reform of education administration in New Zealand. Wellington: Government Printer.

Lythe, C. (1997) Spreading their wings - seven hundred and sixty-seven parents talk about their children's home and early childhood education experiences: A report for the Ministry of Education. Wellington: New Zealand Council for Educational Research

Mansell, R. (1993). Community forum on education in Wellington Eastern Suburbs: A case study in choice and democratic community participation in New Zealand education policy. Unpublished two-paper thesis submitted to Victoria University of Wellington.

McKenzie, D. (1994). The irony of educational review. New Zealand Annual Review of Education, 4, 247-259.

Ministry of Education. (2004a). Background to Network Reviews. Retrieved on June 4, 2004, from <www.minedu.govt.nz>

Ministry of Education. (2004b). Building sustainable schooling networks: The implementation phase for network reviews. Wellington: Ministry of Education.

Ministry of Education. (2004c). Statement of intent 2004-2009. Retrieved on January 6, 2005, from <www.minedu.govt.nz>

Mitchell, D., McGee, C., Moltzen, R., \& Oliver, D. (1993). Hear our voices: Final report of Monitoring Today's Schools Research Project. Hamilton: University of Waikato.

The Treasury. (1987). Government management: Brief to the incoming government 1987. Vol. 2. Educational Issues. Wellington: Government Printer.

Pere, R. (1997). Te wheke: A celebration of infinite wisdom. Gisborne: Ao Ako Global Learning New Zealand.

Robust, T. (2002). Ko te reo te mauri o te mana Māori: The Language is the life essence of Māori existence. In Indigenous languages across the 
community: Proceedings of the Seventh Annual Conference on Stablising Indigenous Languages. Toronto, Canada. ED 462232

Smelt, S. (1998). Today's schools: Governance and quality. Wellington: Victoria University of Wellington.

Wylie, C. (1999). Ten years on: How schools view educational reform. Wellington: New Zealand Council for Educational Research.

\section{The author}

Catherine Savage is a Senior Lecturer in Primary Teacher Education at Victoria University of Wellington. She is working toward completing her Education Doctorate with Massey University. Her current research interests include school network reviews, rural education and special education.

\section{Acknowledgments}

I wish to acknowledge and thank Don Miller for his support and mentoring throughout the development of this manuscript. 